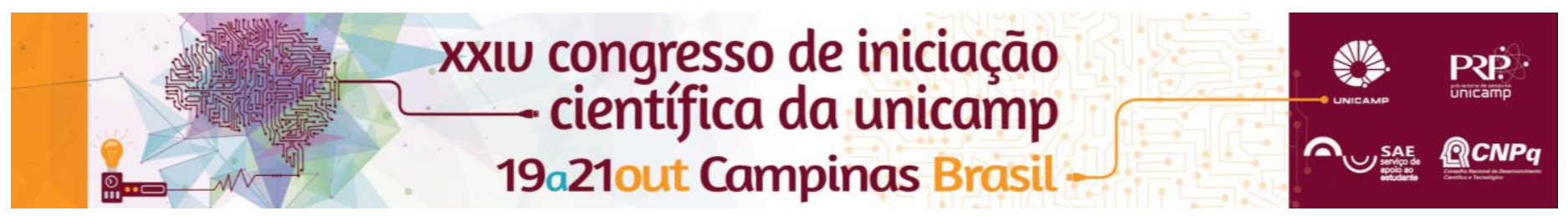

\title{
Visualização interativa para auxílio ao aprendizado do funcionamento de árvores PQR (Parte II)
}

\section{Bruna S. Silva*, Celmar Guimarães da Silva.}

\section{Resumo}

Árvore PQR é uma estrutura de dados que vem sendo utilizada como auxílio no preparo de leiautes de matrizes reordenáveis e dígrafos acíclicos, porém carece de mecanismos de visualização que facilitem analisá-la. Como continuidade de projeto anterior, este trabalho propôs o desenvolvimento de uma ferramenta que possibilite simplificar o entendimento sobre a criação de uma árvore $P Q R$, utilizando representação gráfica interativa. $O$ programa gera vizualizações sobre o processo de formação dessa estrutura de dados de acordo com um conjunto de elementos e um conjunto de restrições de permutação desses elementos.

\section{Palavras-chave:}

Visualização, Estrutura de Dados, Árvores PQR.

\section{Introdução}

Diversas estruturas de dados podem ser encontradas na literatura de Computação, como pilha, fila, grafos e árvores. Algumas possuem ferramentas que possibilitam visualizar como elas funcionam internamente.

Contudo, ainda não foi encontrada na literatura uma ferramenta que representasse o processo de criação de uma estrutura de dados chamada Árvore PQR, apresentada por Telles e Meidanis ${ }^{1}$. Essa estrutura representa permutações de elementos que tentam obedecer a determinadas regras (restrições) de permutação.

Dessa forma, o objetivo desse trabalho foi desenvolver uma ferramenta capaz de mostrar, de forma interativa, o processo de formação dessa estrutura de dados, dando continuidade ao trabalho anterior de iniciação científica de Silva e Silva².

\section{Resultados e Discussão}

Após uma avaliação heurística realizado no software resultante do projeto anterior, foram realizados ajustes na ferramenta interativa com o objetivo de melhorar o entendimento por parte do usuário. $\mathrm{O}$ resultado obtido foi um programa criado para permitir acompanhar o processo de formação de uma árvore $P Q R$, feito pela adição consecutiva de restrições de permutações.

Uttilizou-se a ferramenta Prefuse ${ }^{3}$ para a visualização de grafos hierárquicos de uma maneira interativa e animada. A Figura 1 ilustra uma imagem do programa que desenha árvores PQR, de acordo com os parâmetros inseridos do lado esquerdo da ferramenta.

Os ajustes realizados na ferramenta tinham como objetivo facilitar a interação com o programa e minimizar erros que poderiam existir ao inserir os parâmetros para construção da árvore manualmente. Isso resultou em uma aba para inserção dos elementos que compõem a árvore e das restrições de permutação.

Após os ajustes realizados na ferramenta, foi elaborado um relatório apresentando algumas abordagens para representação de estrutura de dados, descrição sobre árvores $P Q R$, seu processo de criação, metodologias utilizadas para o desenvolvimento da ferramenta e a avaliação feita sobre o programa.

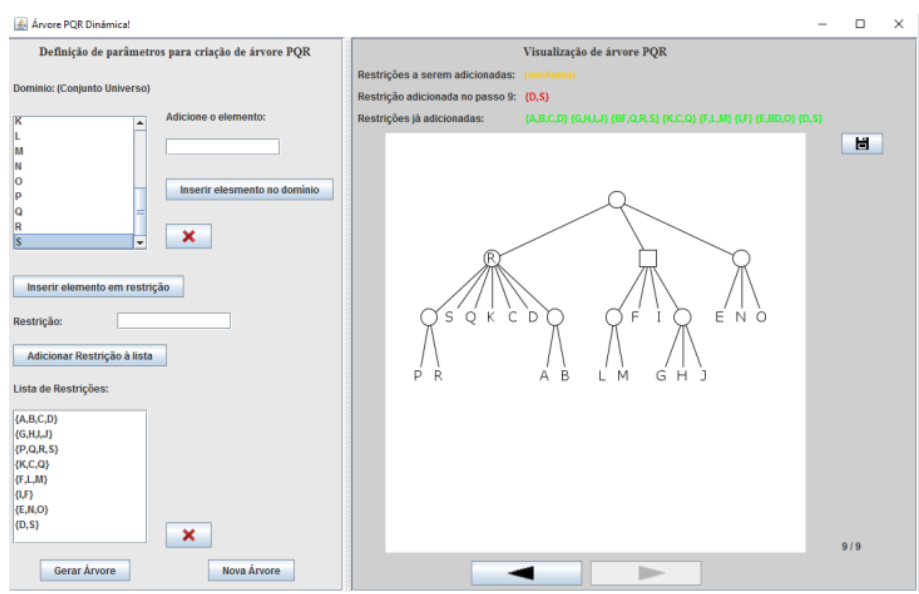

Figura 1. Imagem do programa que gera um desenho dinâmico de árvores PQR.

\section{Conclusões}

A ferramenta desenvolvida permite visualizar 0 processo de formação passo a passo da Árvore PQR a partir de um conjunto de elementos e um conjunto de restrições. Espera-se que o programa desenvolvido facilite o entendimento por parte de pesquisadores e alunos interessados no uso dessa ferramenta.

\section{Agradecimentos}

Ao $\mathrm{CNPq}$ e à PRP/Unicamp, pelo financiamento deste projeto. Ao Prof. João Meidanis (IC/Unicamp) por disponibilizar o pacote PQRTree.jar que implementa árvores $\mathrm{PQR}$.

\footnotetext{
${ }^{1}$ Telles, G.P.; Meidanis, J. Building PQR trees in almost-linear timeEletronic. Notes in Discrete Mathematics, Volume 19, 2005, p. 33-39.

${ }^{2}$ B. S. Silva; C. G. Silva. Visualização interativa para o auxílio ao aprendizado do funcionamento de árvores PQR. Disponível em

http://dx.doi.org/10.19146/pibic-2015-37083. Acesso: 12 de julho de 2016
}

${ }^{3}$ BiD (2012). Prefuse - Information Visualization Toolkit. Disponível em www.prefuse.org. Acesso: 08 de julho de 2016. 